\title{
SOBRE A ARTE DE CRIAR RASCUNHOS: A TRADUÇÃO SEGUNDO JORGE LUIS BORGES
}

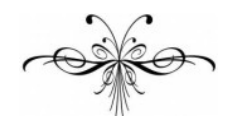

\section{MARIANA CRISTINE HILGERT}

Resumo: As reflexões de Jorge Luis Borges sobre o fazer tradutório se manifestaram de forma irregular em sua obra - seus textos tratando do assunto são independentes, as temáticas são distintas e cada um deles pertence a um período diferente. Além disso, Borges apresenta, em seus textos, reflexões de cunho teórico sobre a tradução, sem nunca, no entanto, ter desenvolvido uma teoria própria. Talvez seja por isso que suas reflexões no âmbito dos Estudos da Tradução ainda estejam tão à margem, beirando quase o desconhecimento, se comparadas às de autores como Friedrich Schleiermacher e Hans Vermeer. A fim de contribuir, mesmo que timidamente, para o reconhecimento do pensamento borgeano sobre tradução, bem como despertar o interesse do leitor pelas complexas reflexões desse autor, nos deteremos a seguir em quatro de seus principais ensaios que abordam o tema: "Las dos maneras de traducir” (1926), "Las versiones homéricas” (1932), "Los traductores de las mil y una noches"(1934) e "Pierre Menard, autor del Quijote” (1939). Alguns de seus apontamentos serão analisados à luz dos conceitos de traduzibilidade, de Walter Benjamin, e de dialogismo, de Mikhail Bakhtin. Dessa forma, pretendemos apresentar, neste artigo, uma nova leitura dos textos de Borges, tendo como base um pensamento do próprio autor: de que como todo escrito, inserindo-se aqui a própria tradução, este artigo nada mais é do que um mero rascunho, em constante processo de recriação.

Palavras-chave: Jorge Luis Borges; tradução; teoria da tradução.

\begin{abstract}
Jorge Luis Borges' reflections on translation are distributed irregularly throughout his work - his texts on the subject are independent from each other their topics differ, and each of them belongs to a specific time period. Plus, in such texts Borges presents theoretical reflections on translation, despite not having developed any particular theory. Perhaps this is why his thoughts are still so marginal in the field of Translation Studies, almost unheard of if compared to those of authors such as Friedrich Schleiermacher and Hans Vermeer. In order to contribute, though timidly, towards a wider recognition of Borges' reflections on translation, and to stimulate the reader's interest in the complex thoughts of that author, this article presents an analysis of four of Borges' most important essays on the topic at hand: "Las dos maneras de traducir" (1926), “Las versiones homéricas” (1932), “Los traductores de las mil y una noches" (1934) and "Pierre Menard, autor del Quijote” (1939). Some of his observations will be analyzed in light of the concepts of translatability, by Walter Benjamin, and dialogism, by Mikhail Bakhtin. Therefore, we aim at presenting a new reading of Borges' writings, one that can be understood by means of a thought by Borges himself: that like any other text, translations included, this article is itself nothing more than a mere draft under a constant process of recreation.
\end{abstract}

Keywords: Jorge Luis Borges; translation; translation studies. 
$\mathrm{P}$ ara o escritor argentino Jorge Luis Borges, traduzir foi uma consequência do próprio meio em que nasceu e viveu. O fato de estar, desde pequeno, em constante contato com o inglês, língua de sua avó paterna, e o espanhol, seu idioma materno, levou-o a fazer a tradução sua primeira - do conto O príncipe feliz, de Oscar Wilde, com apenas nove anos de idade.

Posteriormente, os rumos que Borges tomaria acabariam reconduzindoo à tradução. A partir dos estudos de francês, alemão e latim, em Genebra, onde morou com a família durante seis anos, ele foi dando forma ao interesse que tinha pela área, o que lhe possibilitou traduzir para o espanhol grandes autores da literatura mundial ao longo de toda a sua vida. Entre eles estão Virginia Woolf, William Faulkner, Henri Michaux, Franz Kafka e Walt Whitman.

A partir de suas impressões como tradutor, Borges levantou diversos pontos relevantes em relação ao ato tradutório, sem, no entanto, criar uma teoria própria. Pois, como aponta Cesco (2004, p.82), “para Borges não é necessária uma teoria da tradução; não há nenhum problema quanto à maneira como os homens traduzem, e sim em como traduzir esta ou aquela linha, este ou aquele parágrafo”.

A fim de elucidar as principais reflexões do autor acerca do fazer tradutório, nos deteremos a seguir em quatro ensaios: "Las dos maneras de traducir" (1926), "Las versiones homéricas” (1932), "Los traductores de Las mil y una noches” (1934) e “Pierre Menard, autor Del Quijote” (1939).

\section{Sobre "Las dos maneras de traducir"}

"Las dos maneras de traducir” (1926) é o primeiro texto de cunho teórico do autor dedicado exclusivamente à questão da tradução. O escritor abre o artigo com a já estereotipada expressão italiana traduttore tradittore, cuja frequente atribuição aos tradutores seria suficiente para condená-los, como aponta Borges. Refutando as levianas razões que deram origem a tal sentença, ele afirma simplesmente acreditar em boas traduções e até mesmo na possibilidade de traduzir poesia.

Antes de avançarmos, é preciso apontar a influência do escritor e filósofo alemão Novalis sobre o pensamento borgeano expresso no texto aqui em análise. As reflexões desse autor alemão acerca da linguagem despontam no decorrer do texto de Borges quando este, por exemplo, faz referência às três categorias diferentes de significados que podem, segundo Novalis, ser atribuídos às palavras. A primeira é a categoria de palavras com significados próprios (eigentümliche Bedeutungen); a segunda refere-se aos significados conotativos (Nebenbedeutungen); e a terceira, aos arbitrários (willkürliche Bedeutungen) ${ }^{1}$.

Com base nisso, Borges esclarece que as palavras podem variar no seu significado - especialmente quando se trata de palavras que integram um texto de poesia. Neste caso, "el sentido de una palabra no es lo que vale, sino su ambiente, su connotación, su ademán” (BORGES, 1997 [1926], p.257). É o caso da palavra 'luna', "que [se] para nosotros ya es una invitación de poesía, es des-

\footnotetext{
${ }^{1}$ Os conceitos de Novalis apontados por Borges são encontrados originalmente no seguinte trecho: "Über die Natur des Wortes. Jedes Wort hat seine eigentümliche Bedeutung, seine Nebenbedeutungen, seine falschen und durchaus willkürlichen Bedeutungen”. (NOVALIS, 1929). Disponível em: <http://gutenberg.spiegel.de/buch/6618/23>. Acesso em: 3 ago. 2012.
} 
agradable entre los bosquímanos que la consideran poderosa y de mala entraña y no se atreven a mirarla cuando campean” (p.257).

Assim, os apontamentos de Novalis determinaram

(...) como ele [Borges] examinou as vicissitudes de um texto no decorrer do tempo: os significados de palavras sobrevivem, enquanto que conotações e associações se transformam, até mesmo em línguas e em formas de expressão, pois as mesmas palavras podem ter diferentes conotações para diferentes comunidades linguísticas separadas no espaço ou no tempo. Borges indica com frequência que significados, conceitos e ideias são mais fáceis de transferir de um modo de expressão para o outro do que conotações e associações, nas quais a emoção tem um papel mais relevante (Kristal, 2002, p.16, tradução nossa).

Borges também sugere, em sua reflexão, que a transferência de sentidos não é árdua apenas quando se dá entre dois idiomas diferentes, mas também quando ocorre dentro de uma mesma comunidade linguística e literária. Como exemplo, cita a palavra "súbdito" que "es decente em España y denigrante en América” (BORGES, 1997 [1926], p.257) e o termo "consuelo”, que, extraído de um poema de Martín Fierro, parece atribulá-lo: "La dificultad estriba en la palavra cConsuelo". El diccionario de argentinismos no la considera, ni falta que hace. He oído decir que ese consuelo es algunos pesos. A mí no me convence: ha de ser alguna muchacha, más bien.” (p.257). Assim, deve-se concordar com Waisman, quando este afirma, a partir de sua análise sobre Borges, que os textos, para este autor, "possuem valores diferentes para leitores diferentes, mesmo se esses falarem a mesma língua” (WAISMAN, 2005, p.45, tradução nossa). Afinal, as palavras que compõem esses textos estão vinculadas não somente ao seu valor denotativo, mas também às suas diferentes conotações, submetidas a questões espaço-temporais, como mencionado acima por Kristal - ou seja, onde e quando a obra foi escrita e lida.

Isso nos remete a Borges quando este reanalisa a premissa de que a tradução da obra do norte-americano Edgar Allan Poe El Cuervo (The Raven) nunca poderá provocar sobre os argentinos o mesmo efeito que provocou sobre os seus compatriotas. Segundo Borges, isso não é nem mesmo uma questão relativa à língua, já que a obra do argentino Evaristo Viega, por exemplo, também não será compreendida por um chileno da mesma forma que o foi por um argentino.

Com as constatações acima, percebe-se que Borges, ao escrever o artigo "Las dos maneras de traducir",

(...) já está consciente de que a tradução sempre envolve tais deslocamentos de tempo e espaço em relação ao original, da mesma forma que o original o faz em relação ao momento e o local de sua produção original, e que isso torna a tradução uma metáfora ideal do ato de escrever, bem como um perfeito ponto de partida para lidar com questões de valor estético e diferenças culturais (Waisman, 2005, p.46, tradução nossa).

Outra questão central levantada por Borges em seu artigo diz respeito às duas maneiras de traduzir referidas no título deste. $\mathrm{O}$ autor aponta a existência de duas classes de tradução, uma delas praticando a literalidade e a outra a 
perífrase. A primeira corresponderia ao pensamento romântico, que nos remete ao romantismo literário. Segundo essa perspectiva, no ato da tradução, o autor, ou seja, o criador da obra e tudo aquilo relacionado a ele, é o que há de mais relevante. Dessa forma, seria preciso conservar, na tradução, cada singularidade do escritor no original.

Borges se mostra bastante cético em relação ao pensamento romântico, por saber ser impossível a tão almejada literalidade romântica. Tal fato ele justifica com a seguinte proposição: "Y el hombre (ya se sabe) no es intemporal ni arquetípico, es Diego Fulano, no Juan Mengano, es poseedor de un clima, de un cuerpo, de una ascendencia, de un hacer algo, de un no hacer nada, de un presente, de un pasado, de un porvenir y hasta de una muerte que es suya" (BORGES, 1997 [1926], p.258). Com essa afirmação, cujo conteúdo é recorrente em outros pontos de sua obra, Borges refuta nitidamente a linha romântica de tradução. Para ele, o tradutor, quando se defronta com uma obra, não pode simplesmente colocar de lado todas aquelas características que o diferem, em diversos âmbitos, do chamado escritor original.

A teoria clássica, que remonta às características do classicismo literário, apresenta exatamente o oposto. Segundo ela, é a obra de arte que está acima do artista. Assim, elementos como metáforas, por exemplo, são vistos como uma "obtención de verdad poética, que, una vez agenciada, puede (y debe) ser aprovechada por todos. Cada literatura posee un repertorio de esas verdades, y el traductor sabrá aprovecharlo y verter su original no sólo a las palabras, sino a la sintaxis y a las usuales metáforas de su idioma” (BORGES, 1997 [1926], p.258). Dessa forma, os clássicos, através da perífrase, preferem, ao traduzir, deixar de lado as metáforas e as demais marcas do autor da obra, substituindo-as por aquelas do tradutor.

As duas teorias evocadas por Borges não representam qualquer inovação no âmbito da teoria da tradução. Na verdade, elas correspondem às já consagradas definições de metáfrase e paráfrase, assim denominadas pela primeira vez pelo poeta e dramaturgo inglês John Dryden, já no século XVII. Segundo ele, metáfrase é a tradução "palavra por palavra, linha por linha” (apud JENSEN, 1969, p.78, tradução nossa), enquanto paráfrase é "tradução com amplitude, na qual o tradutor não perde o autor de vista, não sendo as palavras deste, no entanto, tão rigorosamente seguidas quanto o seu sentido, podendo esse também ser ampliado, mas não alterado" (p.83, tradução nossa).

Neste momento, faz-se necessária uma breve explicação. Os termos 'paráfrase' e 'perífrase' acima citados têm sentidos semelhantes, mas não são totalmente correspondentes. Segundo o Dicionário Houaiss Online, 'perífrase' corresponde a "frase ou recurso verbal que exprime aquilo que poderia ser expresso por menor número de palavras; circunlóquio”. O conceito de 'paráfrase', por sua vez, corresponde, entre outras significações, a "interpretação ou tradução em que o autor procura seguir mais o sentido do texto que a sua letra”.

Como dito anteriormente, Borges utiliza o termo perífrase no seu texto, associando-o àquela tradução que se preocupa mais com o sentido e menos com a exatidão das palavras do autor - o que corresponde ao significado de paráfrase no âmbito da tradução, como definido por Dryden e como refere o dicionário Houaiss. Autores como Waisman (2005, p.46) traduzem o termo perífrase diretamente por 'paraphrase' como mostra o exemplo a seguir: "Next, Borges describes the two possile ways of translating, referred to in the title of the article: 
'Una practica la literalidad, la otra la perífrasis. La primera responde a las mentalidades románticas, la segunda a las clásicas.' [One practices literalness, the other paraphrase. The former corresponds to Romantic, and the latter to Classical, mentalities]”. Não é do propósito deste trabalho entrar no mérito dessa distinção de forma aprofundada. É necessário, apenas, que o leitor tenha consciência desses dois termos e que entenda o cruzamento que existe entre ambos. As razões pelas quais Borges, ao escrever o seu artigo, preferiu um termo ao outro, são desconhecidas. No entanto, o sentido que ele dá à perífrase é claro. Diante dessas considerações, perífrase e paráfrase podem ser, no contexto da análise deste artigo, entendidos como sinônimos.

Um dos grandes diferenciais da reflexão apresentada por Borges nesse texto de 1926, não está na apresentação dos dois métodos referidos, mas sim no fato de ele acreditar que "hasta los versos son traducibles" (BORGES, op. cit., p.258). O comentário de Borges é feito timidamente no início do ensaio. Sua relevância, porém, é reforçada pela clássica polêmica que gira em torno dessa questão, a qual pode ser também ilustrada pela opinião de Roman Jakobson sobre o tema. Em seu ensaio "On translation” (1959), este autor apresenta a seguinte visão a respeito da traduzibilidade da poesia:

(...) [a] paronomásia ${ }^{2}$ reina sobre a arte poética (...) [e] a poesia é, por definição, intraduzível. Apenas a transposição criativa é possível: seja uma transposição intralinguística, de uma forma poética para outra, seja uma transposição interlinguística, de uma língua para a outra, ou, finalmente, seja de um sistema de signos para o outro, por exemplo, do verbal para música, dança, cinema ou pintura (1959, p.238, tradução nossa).

Para Jakobson, a poesia seria, então, intraduzível, por essa relação entre fonética e semântica ser ferida. Waisman resume essa ideia da seguinte forma. “(...) Já que a tradução de poesia necessita da dissociação do vínculo existente entre a unidade fonética e a semântica, Jakobson argumenta que esta é acompanhada por uma perda ou do conteúdo ou da forma, bem como da conexão entre os dois (2005, p.49, tradução nossa).

Ao mesmo tempo que Jakobson reconhece a perda, ele parece, por outro lado, enxergar na transposição criativa uma possibilidade para a tradução de poesia. E nesse sentido parece ir também o pensamento de Borges, como veremos em seus próximos escritos apresentados a seguir.

\section{Sobre "Las versiones homéricas"}

Em "Las Versiones homéricas” (1932), Borges aponta as diferenças entre seis traduções de um mesmo trecho da obra Odisseia, de Homero, analisando-as segundo o uso dos adjetivos empregados pelos diferentes tradutores e as maneiras de traduzir (metáfrase versus paráfrase), além de levantar questionamentos a respeito do chamado "texto definitivo".

O ensaio começa com a seguinte proposição: "Ningún problema tan consustancial con las letras y con su modesto misterio como el que propone una

\footnotetext{
${ }^{2}$ A paronomásia é definida, segundo explica Waisman, "pela relação entre as unidades fonéticas e semânticas” (2005, p. 49, tradução nossa).
} 
traducción". Em seguida, o autor afirma que "la traducción parece destinada a ilustrar la discusión estética” (BORGES, 2004 [1932], p.280). Segundo Borges, os mistérios da literatura poderiam ser mais bem compreendidos se analisados à luz da tradução. Por isso, tal como aponta Waisman e segundo afirmamos previamente, a tradução se mostra como, "uma metáfora ideal da escrita, bem como o perfeito ponto de partida para analisar questões de estética e diferenças culturais” (2005, p.46, tradução nossa).

Para ilustrar melhor a relação entre literatura e tradução, Borges recorre à noção de "objeto externo" de Bertrand Russel, definida, no dizer do autor argentino, como "un sistema circular, irradiante, de impresiones posibles” (BORGES, op. cit., p.280). A mesma definição, segundo Borges, pode ser aplicada a um texto, "dadas las repercusiones incalculables de lo verbal” (p.280). Dessa forma o autor deixa claro que, para ele, um texto é algo passível de diferentes e até mesmo incalculáveis interpretações e transformações - estas podendo ser observadas de maneira mais clara nas suas traduções, que nada mais são do que "un parcial y precioso documento de las vicissitudes [que sufre queda en sus traducciones]” (p.280). Assim, para ele, o texto não é um objeto estável, mas móvel, não é definitivo, mas transformável. Nesse sentido, Borges reitera que

presuponer que toda recombinación de elementos es obligatoriamente inferior a su original, es presuponer que el borrador 9 es obligatoriamente inferior al borrador $\mathrm{H}$-ya que no puede haber sino borradores. $\mathrm{El}$ concepto de texto definitivo no corresponde sino a la religión o al cansancio (Ibid, p.280).

Nesse parágrafo, fica clara a posição do autor no que diz respeito à relação entre o original e a sua tradução. Para ele, tanto a primeira quanto a segunda não passam de rascunhos, não podendo, por isso, existirem relações de inferioridade ou superioridade entre elas. São, afinal, iguais, à medida que serão sempre diferentes, sempre mutáveis, jamais definitivas - ou, nas palavras de Borges, "diversas perspectivas de un hecho móvil, (...), un largo sorteo experimental de omisiones y de énfasis” (p.280). Dos Santos Filho resume essa ideia da seguinte forma:

Enquanto rascunhos os textos sempre comportam a possibilidade de correções, ampliando seu horizonte de significação à medida que uma nova tradução é realizada. Trata-se de uma escrita em torno, gerando uma riqueza maior do que o texto original. Contudo, importa ressaltar, a escrita em torno não supõe uma hierarquia para a qual a última tradução é a mais verdadeira porque contém todas as outras. Pelo menos é o que nos parece poder ser inferido da perspectiva clássica de traduzir. Não parece haver hierarquização. O original é um rascunho que abriga infinitas ressalvas, infinitas traduções, como o círculo possui infinitos lados. O ideal romântico de tradução é recusado, pois ao tradutor não se impõe a exigência da fidelidade literal, até porque o câmbio de uma língua a outra impediria a correspondência entre as palavras. Entre o tradutor e a tradução não há a mediação do original, entendida no sentido de portador da verdade (Dos Santos Filho, 2009, p.20).

A quebra do paradigma da hierarquização entre o original e as traduções levanta questionamentos que abalam valores já bastante enraizados em nós 
mesmos, conforme aponta Waisman): "Como isso afeta aquilo em que acreditamos em relação à tradição e influência, à transmissão de cultura, à representação e subjetividade, a centro e periferia?” (2005, p.51, tradução nossa). Segundo este autor, tal mudança de valores pode ter diversas consequências, em diversos âmbitos. No caso de Borges, “a ideia de que o 'texto definitivo' é uma falácia torna-se um aspecto fundamental do sistema internacional de citações e alusões, verídicas e, também, apócrifas, encontradas em toda a sua obra de ficção” (p.51, tradução nossa).

A convicção de Borges quanto à inexistência de um texto definitivo pode ser relacionado à sua própria visão de literatura, que, segundo Waisman, pode ser metaforicamente descrita como uma sala de espelhos, em que é impossível diferenciar o original de seus espelhos (2005, 51-52). No conto "La biblioteca de Babel” (2011 [1941]), podemos encontrar as origens desse pensamento de Borges trazido à tona por Waisman. Nele, o autor argentino explica que o universo

(que otros llaman de Biblioteca) se compone de un número indefinido, y tal vez infinito, de galerias hexagonales (...). Desde cualquier hexágono se ven los pisos inferiores y superiores: interminablemente (...). En el zaguán hay un espejo, que fielmente duplica las aparienciais. Los hombres suelen inferir de ese espejo que la Biblioteca no es infinita (si lo fuera realmente ¿̇a qué esa duplicación ilusoria?); yo prefiero soñar que las superficies bruñidas figuran y prometen el infinito...

A biblioteca descrita por Borges se sugere como metáfora da própria literatura. A representação daquela como uma galeria infinita de imagens que se repetem - como uma sala de espelhos, enfim - nos parece ser, também, uma bela alegoria das reflexões do pensador e linguista russo Mikhail Bakhtin, para quem

os enunciados [neste caso, as obra literárias] não são indiferentes uns aos outros nem são autossuficientes; conhecem-se uns aos outros, refletem-se mutuamente. São precisamente esses reflexos recíprocos que lhes determinam o caráter. O enunciado está repleto dos ecos e lembranças de outros enunciados, aos quais está vinculado no interior de uma esfera comum da comunicação verbal. $\mathrm{O}$ enunciado deve ser considerado acima de tudo como uma resposta a enunciados anteriores dentro de uma dada esfera (a palavra "resposta” é empregada aqui no sentido lato): refuta-os, confirma-os, completa-os, baseia-se neles, supõe-nos conhecidos e, de um modo ou de outro, conta com eles (Bakhtin, 1997, p.316).

Essa reflexão de Bakhtin leva a pensar que toda a obra que faz o papel de resposta precisa estar necessariamente vinculada à outra obra, esta, por sua vez, exercendo o papel de "pergunta", que, por sua vez, exercera, antes, o papel de resposta, e assim por diante, numa infinita cadeia discursiva. Esse vínculo, no entanto, não é visível, ou seja, não é possível apontar exatamente entre quais obras esse diálogo se dá. Ou seja, não há como determinar o "texto adâmico”, o que veio primeiro, tendo dado origem aos demais. Bakhtin batizou este processo de dialogismo. Segundo ele, 
a orientação dialógica é naturalmente um fenômeno próprio a todo discurso. Trata-se da orientação natural de qualquer discurso vivo. Em todos os seus caminhos até o objeto, em todas as direções, o discurso se encontra com o discurso de outrem e não deixa de participar, com ele, de uma interação viva e tensa. Apenas o Adão mítico que chegou com a primeira palavra num mundo virgem, ainda não desacreditado, somente este Adão podia realmente evitar por completo esta mútua orientação dialógica do discurso alheio para o objeto. Para o discurso humano, concreto e histórico, isso não é possível: só em certa medida e convencionalmente é que pode dela se afastar (Bakhtin, 1988, p.88).

Tal qual afirmamos acima, é possível entender a metáfora de inspiração borgiana - da literatura como uma sala de espelhos - como uma bela ilustração do dialogismo de Bakhtin. Mas de que forma é possível associar a tradução a esse processo? Um recurso para esse fim encontra-se nas reflexões do linguista belga André Lefevere, que associou o ato de traduzir ao termo 'refração'. Como 'reflexão', 'refração' é um termo recorrente na Física utilizado para explicar um fenômeno que ocorre com a luz quando essa entra em contato com uma superfície. Diz-se que há reflexão quando a luz volta para o mesmo meio de onde se originou, e ocorre refração quando a luz passa do meio de onde se originou para outro, propagando-se.

Assim, segundo Lefevere, um texto sofre refração à medida que é escrito novamente dentro de um novo contexto, diferente daquele no qual foi originalmente produzido. Nas palavras de Gross (2001, p.159, tradução nossa), "refrações de obras literárias escritas são textos que foram descontextualizados e, posteriormente, recontextualizados num novo meio". Os textos refratados, que podem ser, além de textos escritos, "filmes, peças, revistas em quadrinho, pinturas, composições musicais” (LEFEVERE, 1984, apud GROSS, 2001, p.159, tradução nossa), não são nem jamais serão iguais ao texto original, mas permanecerão sempre ligados. No entanto, o fato de não serem “originais” faz com que, por vezes, sejam desqualificados ou avaliados com menosprezo, como pertencentes a uma categoria inferior. Tal atitude perante os textos refratados é falaciosa, especialmente porque são estes os grandes responsáveis pela perpetuação da obra, pela sua sobrevivência. Nesse caso, a tradução cumpriria uma tarefa redentora e messiânica, como explica Furlan (1997) - em referência ao artigo de Benjamin, “A tarefa do tradutor” (1923) -, capaz de permitir a "sobrevida da obra” traduzida.

Também este autor, Walter Benjamin, pode ser associado às reflexões de Borges em relação à tradução. Segundo o tradutor e filósofo alemão, cada obra é portadora de uma tradução virtual, a qual já se encontra nas suas entrelinhas. É como se cada obra trouxesse consigo a explicitação de uma compreensão, algo que permanece em estado latente até ser desvelado pelo seu tradutor. Tal fenômeno é chamado de traduzibilidade, como Benjamin elucida (2008, p.27) ${ }^{3}$ : “O fato de a traduzibilidade ser própria de certas obras não significa que a sua tradução lhes seja necessária e essencial, mas sim que um determinado significado, existente na essência do original, se expressa através da sua traduzibilidade”.

\footnotetext{
${ }^{3}$ No presente trabalho, foi utilizada a tradução de Fernando Camacho do texto de Walter Benjamin, "Die Aufgabe des Übersetzers".
} 
Segundo nossa leitura, Borges parece sugerir que essa capacidade de tradução e recriação da obra é tão infinita quanto o número de tradutores que essa obra possa ter, sendo cada tradução uma nova interpretação da mesma obra. Essa ideia fica clara, por exemplo, no seguinte questionamento do autor, já referido previamente: “¿Qué son las muchas de la Ilíada de Chapman a Magnien sino diversas perspectivas de um hecho móvil, sino um largo sorteo experimental de omisiones y de énfasis?” (BORGES, 2004 [1932], p.280)

As "diversas perspectivas" representam, por um lado, as diferentes formas de visualizar, isto é, de interpretar a obra. Estas podem ser, porém aplicadas também a um mesmo âmbito linguístico, como reafirma o autor. "No hay essencial necesidad de cambiar de idioma, ese deliberado juego de la atención no es imposible dentro de una misma literatura” (p.280). Isso é possível por se tratar de uma questão que toca no mérito da linguagem. Por essa razão, a asserção borgeana pode ser facilmente vinculada aos pensamentos de Jacques Derrida. Para o filósofo de origem argeliana, analisado por Goulart, é mais relevante

pensar no quanto as palavras podem significar e não no que elas significam. É por isso que a linguagem, na riqueza de seus diferentes significados, nas ambiguidades que tais diferenças necessariamente trazem e nos jogos de associação que eles ensejam, realiza operações tão múltiplas que jamais se poderá pensar, por exemplo, num significado fixo ou numa interpretação única para um texto (Goulart, 2003, p.6).

Assim, pode-se dizer que cada tradutor, com sua peculiaridade específica e como defensor de uma possibilidade de tradução, dá luz a um novo sentido, sentido este já presente no original.

Interessante é também outra premissa de Borges, segundo a qual a tradução não representa necessariamente uma perda, nem pode ser classificada como uma categoria inferior à obra primeira. Afinal, como aponta o próprio título do seu texto, as diferentes traduções são apenas diferentes versões de uma mesma obra - todas, ao fim, apenas rascunhos.

Borges ilustra essa afirmação comparando as suas leituras da obraprima de Cervantes, Dom Quixote, e da de Homero, Odisseia, tema central do artigo. A primeira, escrita originalmente em espanhol, representa para ele, como falante nativo do idioma, "un monumento uniforme, sin otras variaciones que las deparadas por el editor, el encuadernador y el cajista” (BORGES, 2004[1932], p.281).

O texto de Homero, por sua vez, "gracias a mi oportuno desconocimiento del griego, es uma librería internacional de obras en prosa y verso”(p.281), dado que cada nova tradução, por trás ao qual se escondem um tradutor e um momento específicos da língua inglesa, representa, também, uma nova obra. Mas não só por esse fator: segundo Borges (p.281), esta "riqueza heterogénea y hasta contradictoria” deve ser atribuída também, e talvez, majoritariamente, à "dificultad categórica de saber lo que pertenece al poeta y lo que pertenece al linguaje. A esa dificultad feliz debemos la possibilidad de tantas versiones, todas sinceras, genuinas y divergentes".

Essa dificuldade - afinal, o que pertence ao autor, o que pertence à linguagem presente? - é explicada por Waisman: 
É impossível determinar em qual ponta do espectro está, na obra de Homero, a ênfase: se mais próxima do poeta, do significado, do espírito do texto (segundo a intenção de Homero), ou se mais perto da língua, da gramática e da sintaxe (inerente à língua naquele momento, a língua como parte de um contexto histórico e cultural), que determina de que forma um texto significa (2005, p.53, tradução nossa).

Nos parágrafos seguintes de "Las versiones homéricas”, Borges apresenta as variações que existem entre as traduções de um trecho do livro XI da Odisseia. Além da variação dos adjetivos - que é uma peculiaridade de Homero, como ressalta Dos Santos Filho (2009) -, Borges aponta que alguns tradutores se mostraram mais adeptos da prática da perífrase, enquanto outros, mais direcionadas à metáfrase. De acordo com Schwartz (2001, p.192), “de todas elas, percebe-se a admiração por aquela em que há uma grande interferência do tradutor, no caso a de Alexander Pope, que ele considera extraordinária, e, em contraposição, uma aceitação resignada da versão correta - "morna”, porém “fiel” de Butler, de 1900”. Dessa forma, Borges explicita sua preferência pela prática clássica da tradução, no âmbito da qual o tradutor também é autor.

Ao final do texto aqui em análise podemos imaginar o leitor se perguntando: afinal, qual das traduções apresentadas é fiel? A resposta do autor argentino é clara: "Repito que ninguna o que todas. Si la fidelidad tiene que ser a las imaginaciones de Homero, a los irrecuperables hombres y días que él se representó, ninguna puede serlo para nosotros; todas, para un griego del siglo diez" (BORGES, 2004 [1932], p.285). E isso se deve ao fato de o tradutor de hoje, como afirma Schwartz (2001), por não ter vivido naquele período da história, conseguir transpor na sua tradução apenas uma simulação daquele tempo.

\section{Sobre "Los traductores de Las mil y una noches"}

Assim como quando discute a Odisseia de Homero, Borges também baseia suas observações de "Los traductores de las mil y una noches” (1936) sem dominar o idioma no qual foi escrita a obra original. Ou seja, assim como o grego, também o árabe lhe era desconhecido, o que sinaliza algo de seu pensamento sobre a tradução:

O fato de que ele tenha escrito seus dois melhores ensaios acerca da tradução, sobre textos cujo idioma ignorava plenamente, é um exemplo da familiaridade irreverente com que Borges se movia pela literatura, mas explica também por que nesses dois casos a fidelidade ao texto original não o preocupava em absoluto (Cesco, 2004, p.88).

Borges inicia seu ensaio citando a tradução de Jean Antoine Galland, publicada entre 1707 e 1717 para o francês, e informando que foi "la peor escrita de todas, la más embustera y más débil, pero fue la mejor leída” (BORGES, 2004 [1936], p.474). Em outras palavras, apesar da discutível qualidade da obra, foi com base nela que o mundo ocidental teve, em 1704, seu primeiro contato com a magia do Oriente. Interessante, no entanto, é que "nenhuma dessas histórias foi encontrada nos manuscritos árabes remanescentes, escritos antes de a tradução de Galland de As mil e uma noites ser publicada” (IRWIN, 1994, p.17, tradução nossa). Tais histórias acabaram integrando a obra de tal forma que os 
próprios sucessores de Galland não tiveram coragem de omiti-las, como relata Borges (op. cit., p.474). Assim, a "originalidade” da obra perdeu seu real valor, dado que a própria versão de Galland foi retraduzida para diversas outas línguas, sendo ela também "uma tradução de um texto anterior, sendo este também uma compilação de histórias anônimas, cuja origem é desconhecida” (WAISMAN, 2005, p.66, tradução nossa).

Já no século XIX, os textos em árabe são revisitados por Edward Lane, que os traduz para o inglês. A peculiaridade de Lane é que ele, na sua honradez, como comenta Borges, tenta constantemente purificar a obra, não lhe faltando coragem para acabar com certos trechos dela que "no pueden ser purificados sin destrucción” (BORGES, op. cit., p.476). A tradução de Lane é, assim, permeada por notas explicativas, nas quais destaca o fato de ter excluído certos elementos em sua tradução. Assim, segundo o próprio Borges (p.477), "es muy sabido que [Galland e Lane] desinfectaron las Noches", no sentido de adaptar a obra ao público que a leria.

O terceiro tradutor mencionado por Borges é Richard Burton, que traduziu a obra para o inglês em 1885. Segundo Borges (p.481), "recorrer Las mil y una noches en la traslación de Sir Richard no es menos increíble que recorrerlas vertidas literalmente del árabe y comentadas por Simbad el Marino”. Com essa afirmação, Borges já explicita sua preferência pela versão de As Mil e uma Noites de Burton, razão que reside essencialmente no fato de este tradutor alcançar "um efeito de hiper-fidelidade, na medida em que executa uma série de infidelidades criativas. A questão-chave se encontra numa certa irreverência em relação ao original e ao potencial criado pelos deslocamentos temporais e espaciais entre o original e a tradução, entre uma versão e outra” (WAISMAN, 2005, p.69, tradução nossa).

Tal "hiper-fidelidade" atingida por meio de "infidelidades criativas" é, na realidade, um grande paradoxo, como avalia Waisman (2005). Mas é justamente essa ousadia de Burton que é admirada por Borges, leitor atento de diversas versões da obra em espanhol, inglês, alemão e francês - talvez pelo fato de não tentar esconder a realidade, mas ampliá-la. Segundo Costa, que parece sintonizar com essa perspectiva,

Borges, longe dos críticos que caçam erros ou dos novos teóricos que defendem a visibilidade do tradutor, está à procura de traduções que revelem aspectos que estão em estado virtual no original, mas que só podem aparecer quando se dão duas condições: que a língua tenha experimentado formas literárias diversas e que o autor traga essas formas para dentro da obra traduzida (Costa, 2005, p.175).

Assim, pode-se dizer que Burton permitiu a florescência de tais aspectos virtuais, em estado latente na obra, através de sua tradução. Além disso, o tradutor conseguiu resolver uma questão considerada crucial pelo autor argentino: o de "interessar a caballeros britânicos del siglo XIX com la version escrita de cuentos musulmanes y orales del siglo XII" (BORGES, 2004 [1936], p.481). De que forma? Readmitindo todos os detalhes eróticos que haviam sido refutados por seu antecessor puritano, Edward Lane. No entanto, o mais relevante do comentário de Borges é o destaque que dá ao receptor, isto é, ao leitor da tradução, bem como a condição desse leitor no espaço e no tempo. 
O próximo tradutor analisado por Borges é J. C. Mardus, que, em 1899, recompôs a obra em francês. Borges (p.485) aponta-o como sendo "el traductor más veraz" de As Mil e uma noites, e cuja "genial literalidad [es] muy demostrada por el inapelable subtítulo Versión literal y completa del texto árabe y por la inspiración de escribir Libro de las mil noches y una noche”.

Borges, no entanto, mostra-se cético em relação a essa literalidade. Esse ceticismo é resumido por Cesco (2004, p.89) da seguinte forma: “Não há maior ficção que acreditar no que o literal evoca: a correspondência exata entre as línguas; entre um objeto e a palavra e o que a palavra representa; entre o que a linguagem diz e o que quer dizer”.

Assim, para o autor argentino, da mesma maneira que Burton, Mardus também se mostra infiel, à medida que, por exemplo, "no traduce las palavras sino las representaciones del libro: libertad negada a los traductores, pero tolerada em los dibujantes” (BORGES, op. cit., p.489). O escritor argentino faz, aqui, menção aos tantos detalhes que Madrus acrescenta na sua tradução, sem, no entanto, julgá-lo por isso. Segundo ele, "su infidelidad, su infidelidade creadora y feliz, es lo que nos debe importar” (p.490).

Em seguida, Borges adentra no mundo das traduções para o alemão, detendo-se especialmente na versão de Enno Littmann, realizada entre 1923 e 1928. Borges (p.492) o descreve como sendo "de una franqueza total. No lo retraem las obscenidades más inefables (...) No omite uma palavra (...). Desatiende o rehúsa el color local; (...) Es siempre lúcido, legible, mediocre”.

A partir desses comentários, Borges se mostra visivelmente desapontado com a tradução de Littmann - apesar de esta constar como a melhor dentre as já publicadas, segundo a Enciclopédia Britânica (p.494). Este descontentamento de Borges se dá talvez pelo fato de à literatura alemã pertencerem apenas obras "fantásticas", como ele mesmo as descreve. Assim, o fato de a versão de Littman conter nada mais do que a "probidad de Alemania" é quase uma afronta à capacidade alemã de produzir literatura. Com base nisso, Borges (p.493) questiona: "Que no haría un hombre, un Kafka, que organizara y acentuara esos juegos, que los rehiciera según la deformación alemana, según la Unheimlichkeit de Alemania?”.

\section{O conflito Newman-Arnold e o tradutor como leitor}

De forma sucinta, o artigo de Borges sobre os tradutores de As mil e uma noites se detém em dois pontos principais. O primeiro diz respeito às formas de traduzir escolhidas pelos diferentes tradutores, questão ilustrada pelo conflito - ou, nas palavras de Borges, pela "hermosa discusión” - entre os ingleses Francis Newman (1805-1897) e Matthew Arnold (1822-1888), ambos tradutores de Homero, e comentada por Borges em meio às suas análises sobre os tradutores das Noches. A disputa ocorre, pois Newman se mostra, através de suas traduções, mais favorável à literalidade, ou à metáfrase, enquanto Arnold apoia a tradução mais fiel ao espírito do texto, ou a paráfrase, como já explicitado anteriormente. A discussão dos dois se dá em torno dessas duas estratégias. No debate, a única verdade comum para ambos é a de que não é possível ser fiel às duas práticas ao mesmo tempo (WAISMAN, 2005).

Com isso, voltamos novamente à discussão clássica que se dá em torno dessas práticas tradutórias com concepções antagônicas. Embora tenha se mos- 
trado sempre mais favorável à prática clássica da paráfrase, como fica visível no seu primeiro artigo, de 1926, Borges parece preferir uma relativização, tentando evitar cunhar qualquer uma das práticas como certa ou errada. Assim, “embora Newman e Arnold abordem a tradução de formas opostas e contraditórias, Borges sugere, paradoxalmente, que ambas são, na realidade, válidas” (p.55, tradução nossa). Cada uma dessas práticas é apenas responsável por consagrar uma dessas possibilidades e acarreta em diferentes consequências para a tradução: enquanto a postura de Arnold "puede suministrar los agrados de la uniformidade y la gravedad", a literalidade de Newman pode "[suministrar los agrados] de los contínuos y pequeños assombros” (BORGES, 2004 [1936], p.477)

Essa "validade" de ambas as versões se justifica pelas diferentes vantagens que cada uma delas apresenta. Assim, enquanto Newman retém, através da literalidade que emprega, todas as nuances e singularidades, Arnold prefere eliminar quaisquer detalhes que possam distrair o leitor.

Também o fato de cunhar a discussão entre Newman e Arnold como "hermosa" marca o valor estético que a tradução tem para o autor argentino, sendo seu propósito, tanto neste artigo quanto em "Las versiones homéricas", destacar os “"prazeres' estéticos que acompanham cada uma das maneiras de traduzir” (WAISMAN, 2005, p.55, tradução nossa).

O segundo ponto levantado pelo autor em seu ensaio sobre os tradutores de As mil e uma noites diz respeito ao papel do tradutor como um leitor que congela, em sua tradução, um momento tanto pessoal quanto da própria cultura na qual vive e que se encontra por trás de seu trabalho, sobretudo no que diz respeito à literatura do país. As obras dos diferentes tradutores de As mil e uma noites não podem ser, assim, dissociadas desse meio e sobretudo, nas palavras de Cesco, "da particular concepção da literatura que domina na sua língua" (p.86). Dessa forma, Borges afirma que "las versiones de Burton y de Madrus, y aun la de Galland, sólo se dejan concebir después de una literatura. Cualesquiera sus lacras o sus méritos, esas obras características presuponen un rico proceso anterior” (BORGES, op. cit., p.492), processo esse que é marcado pelo histórico literário de uma cultura.

Dessa forma, é possível definir cada tradução - neste caso, cada uma das versões de As mil e uma noites - como uma nova leitura da obra, imbuída no tempo e no espaço daquele que a traduz e sobreposta por diferentes vozes literárias - ou reflexos, se lembrarmos da ideia de literatura a partir da metáfora da sala de espelhas. E, à medida que mais traduções são realizadas, mais vão se revelando os mistérios escondidos dentro da primeira obra, que, durante esse processo, vai se ampliando continuamente. Tal processo de desvelamento pode ser relacionado à noção de traduzibilidade, do alemão Walter Benjamin, como já mencionado anteriormente.

\section{Sobre "Pierre Menard, autor del Quijote”}

O conto "Pierre Menard, autor del Quijote" foi publicado pela primeira vez em 1939, no jornal argentino Sur. Dois anos mais tarde, passou a fazer parte da coleção de textos de Borges reunidos sob o título El Jardin de senderos que se bifurcan. Em 1944, foi integrado à obra Ficciones e, em 2004, às Obras completas do autor, consagrando-se como um dos melhores textos de Borges 
acerca da tradução, pondo-o até no mesmo nível de textos de autores como Walter Benjamin (KRISTAL, 2006).

Nesse conto, o narrador se apresenta como sendo um amigo do francês Pierre Menard, e declara ter, por meio do presente artigo, dois intuitos. O primeiro seria o de corrigir as falhas de enumeração das obras de seu amigo artista, apresentadas num suposto catálogo. A partir disso, o narrador cita o que ele chama de obras visíveis de Menard, entre as quais se encontram sonetos, monografias, artigos, traduções, rascunhos, prefácios etc.

Em seguida, o narrador se detém na obra "subterránea, la interminablemente heroica, la impar” (BORGES, 2004 [1939], p.532) de Menard, avaliada por aquele como sendo "talvez la más significativa de nuestro tiempo" (p.532). Esta corresponderia aos capítulos nove e vinte e três, além de um trecho do capítulo vinte e dois da obra-prima do espanhol Miguel de Cervantes, Dom Quixote. E aqui o narrador introduz o que seria o objetivo principal do artigo: justificar a absurda suspeita de que Menard tivesse escrito novamente alguns fragmentos do Quixote.

A genialidade de Borges por trás deste conto é o fato de ele criar um personagem que pretende escrever o Quixote - não outro, mas sim o mesmo -, sem, no entanto, copiá-lo. Como explica o narrador, "su admirable ambición era producir unas páginas que coincidieran - palabra por palabra y línea por línea con las de Miguel de Cervantes” (p.533).

Para atingir tal objetivo, Menard analisa diferentes métodos. O primeiro que lhe ocorreu se resumia a "conocer bien el español, recuperar la fe católica, guerrear contra los moros o contra el turco, olvidar la historia de Europa entre los años de 1602 y de 1918, ser Miguel de Cervantes” (p.534). A inviabilidade desse método não era, no entanto, o que mais o assustava. Para ele, dentre todos os métodos que pareciam inviáveis, esse era o que menos lhe atraía. Para Menard, "ser de alguna manera Cervantes y llegar al Quijote le pareció menos arduo - por consiguiente, menos interesante - que seguir siendo Pierre Menard y llegar al Quijote, a través de las experiencias de Pierre Menard” (p.534).

Em seguida, o narrador passa a comparar trechos da obra de Cervantes com a de Menard. A primeira foi escrita por um espanhol do século XVII, num espanhol do século XVII, para leitores do século XVII, enquanto a segunda, embora escrita também num espanhol do século XVII, fora feita por um francês e seria lida por leitores do século XX. É aí que está a grande diferença entre uma obra e outra, já que, aparentemente, no restante, ambas seriam idênticas em cada palavra e linha.

Tal questão fica visível quando o narrador aponta o mesmo trecho das duas obras, escritos no mesmo espanhol, de forma absolutamente idêntica. Uma ironia de Borges, por trás da qual se esconderia um dos objetivos do autor com esse conto: mostrar que a mais literal das traduções será sempre distinta na medida em que cada leitor é diferente e localiza-se num contexto espaço-temporal também distinto, condição que também define sua leitura. Nas palavras de Dos Santos Filho (2009, p.25), "a tradução-clone sugere que a questão principal é a singularidade da tradução em relação ao destinatário. Traduzir é, assim, atualizar uma obra, ainda que não implique acréscimos, decréscimos ou quaisquer modificações".

A seguir, o narrador avalia a realização - ou a repetição - de Menard como algo complexo e até mesmo fútil, a que este, num idioma estrangeiro, te- 
ria se dedicado. Com isso, Menard teria, como elucida o narrador, multiplicado os rascunhos, o que talvez seja aqui mencionado apenas em relação aos seus manuscritos, mas serve também pare lembrar o leitor de que a obra do francês, como toda e qualquer obra, não passa de mais um rascunho.

Ao fim, o amigo de Menard aponta ser permitido "ver en el Quijote 'final' una espécie de palimpsesto, en el que deben translucirse los rastros - tenues pero no indescifrables - de la 'previa' escritura de nuestro amigo" (BORGES, 2004 [1939], p.538). Esta ideia de palimpsesto apresentada por Borges é interpretada, por Gil (2007) como "uma sobreposição de diferentes leituras do mesmo leitor, até ele descobrir o verdadeiro Quixote” (p.320, tradução nossa). A cada nova leitura, novas possibilidades de interpretação se abrem ao leitor, e ele vai atualizando sua própria compreensão.

Arrojo, por sua vez, se utiliza do termo "palimpsesto" para levantar um outro aspecto, que é o de uma "nova produção textual” (p.320), como sugere Gil. Vejamos, a seguir, como a autora compreende este termo:

Segundo os dicionários, o substantivo masculino palimpsesto, do grego palimpsestos ("raspado novamente"), refere-se ao "antigo material de escrita, principalmente o pergaminho, usado, em razão de sua escassez ou alto preço, duas ou três vezes [...] mediante raspagem do texto anterior". Metaforicamente, em nossa "oficina", o "palimpsesto" passa a ser o texto que se apaga, em cada comunidade cultural e em cada época, para dar lugar a outra escritura (ou interpretação, ou leitura, ou tradução) do “mesmo” texto” (Arrojo, 1986, p.23)

O "palimpsesto" de Arrojo é o novo texto que surge, a nova intepretação que se apresenta, e parece não levar em consideração a sobreposição de leituras sugerida por Gil. Ambas as interpretações nos levam, porém, a questionar a ideia da autoria. Afinal, a construção da obra do ponto de vista da significação se dá de forma praticamente independente a ela, por estar associada, antes, aos seus leitores, aos seus tradutores e às suas respectivas leituras. Seria, então, a figura do autor uma grande falácia? Ou talvez caiba, antes, a pergunta: quem não é autor? Tanto o tradutor como o leitor podem ser classificados como autores, à medida que contribuem num processo de reconstrução ou ressignificação do texto. Ou, segundo Campos (2008), talvez seja o autor apenas um "personagem inventado por todo o texto", bem como o leitor, "outro personagem desejado por todo o texto".

\section{Conclusão}

Com base nos quatro artigos de Jorge Luis Borges apresentados no presente trabalho, pode-se constatar a importância e a relevância que suas reflexões tiveram e continuam tendo na área dos estudos de traduções. É perceptível, no entanto, que seus escritos são pouco reconhecidos neste campo. Tal fato se deixou comprovar pela dificuldade com a qual nos defrontamos no período de busca de bibliografia sobre Borges e sua relação com a tradução.

No entanto, outro fato, este por sua vez positivo, também acabou se comprovando verdadeiro durante o desenvolvimento deste trabalho: apesar de Borges ter elaborado seus escritos à margem do grande centro europeu, distante 
de pensadores contemporâneos consagrados, como Walter Benjamin, por exemplo, é possível perceber pontos comuns e ideias similares nas obras destes autores.

Benjamin, porém, não é o único exemplo: obras de pensadores como Jacques Derrida e Mikhail Bakhtin também se entrecruzam com os escritos de Borges. Juntos eles se permitem um desenvolvimento mútuo, e ampliam, por conseguinte, as fronteiras dos estudos na área. Da mesma forma, este trabalho espera poder ter despertado o interesse para o pensamento de Borges no âmbito da tradução, bem como ter servido de impulso para pesquisas ainda mais ricas e aprofundadas de sua obra.

Mariana Cristine Hilgert marianahilgert@gmail.com Mestranda, Ruprecht-Karls-Universität Heidelberg 


\section{Referências bibliográficas}

Arrojo, Rosemary. Oficina de tradução: a teoria na prática. São Paulo: Editora Ática, 1986.

BAKHTin, Mikhail. Estética da criação verbal. Tradução do francês: Maria Ermantina Galvão Ferreira. São Paulo: Martins Fontes, 1997

. Questões de literatura e de estética: a teoria do romance. São Paulo: Editora da UNESP e Hucitec, 1988.

Benjamin, Walter. "A tarefa do tradutor”. Tradução do alemão: Fernando Camacho. In:

HeIDERMANN, Werner (Org.). Clássicos da teoria da tradução. Florianópolis: UFSC/ Núcleo de tradução, 2001. v. 1. p.26-49. Antologia bilíngue, alemão-português.

BORGES, Jorge Luis. Obras completas. Barcelona: Emecé, 2004. . Textos recobrados (1919-1929). Barcelona: Emecé, 1997. . Cuentos completos. Lumen, 2011. . Un ensayo autobiográfico. Edición del centenário (1899-1999). Barcelona: Emecé, 1999.

Borges, Jorge Luis; FERRARI, Osvaldo. "Lesen ist denken mit fremdem Gehirn: Gespräche über Bücher und Borges”. Zurique: Arche, 1990.

BrANCO, Lucia Castello (Org.). A tarefa do tradutor, de Walter Benjamin- quatro traduções para o português. Belo Horizonte: Fale/UFMG, 2008 (p.25-49).

CAmpos, Alexandre Silveira. A Máscara Vazia: um comentário sobre "Pierre Menard, autor del Quijote”. Revista Espaco Acadêmico, n. 90, nov. 2008. Disponível em: <http://www.espacoacademico.com.br/090/90 campos.htm\#_ftn1>. Acesso em: 28 Mai. 2013.

CEsco, Andréa. "Borges e a tradução”. In: Cadernos de tradução, Florianópolis, v.1., n. 13, 81-97, 2004

CostA, Walter Carlos. “Borges, o original da tradução”. In: Cadernos de Tradução, v. 1, n. 15 . Santa Catarina: 2005. p. 163-183. Disponível em: <http://www.periodicos.ufsc.br/index.php/traducao/article/view/6587/61 31>. Acesso em: 28 Mai. 2013.

Dos SAntos Filho, Andrelino Ferreira. Entre Borges e Benjamin: o elogio da tradução na Medeia de Eurípedes. Belo Horizonte: UFMG, 2009.

FurLAN, Mauri. "Linguagem e tradução em Walter Benjamin”. 1997. In: Anais do XI Encontro Nacional da Anpoll, João Pessoa, PB, 1996. (p.551556).

GIL, Alberto. "Hermeneutik und Übersetzungskritik. Zu Jorge Luis Borges' Pierre Menard, autor del Quijote. In: GIL, Alberto; WIENEN, Ursula (Org). Multiperspektivische Fragestellungen der Translation in der Romania. Frankfurt am Main: Peter Lang, 2007, p. 313-329.

Goulart, Audemaro Taranto. Notas sobre o desconstrucionismo de Jacques Derrida. Belo Horizonte: PUC-Minas, 2003.

GROSS, Joan. Speaking in other voices: an ethnography of Walloon puppet theaters. John Benjamins Publishing Company, 2001.

HouAiss, Antonio et al. Dicionário Houaiss da língua portuguesa online. Disponível em: <http://biblioteca.uol.com.br/>. Acesso em 28. Mai. 2013. 
IRWIN, Robert. The arabian nights: a companion. London: Allen Lane, 1994.

Jensen, H. James. A glossary of John Dryden's critical terms. Minneapolis: University of Minnesota Press, 1969.

KRISTAL, Efraín. Invisible work: Borges and Translation. Nashville: Vanderbilt University Press, 2002.

NovALIS. Fragmente. Jess Verlag, 1929. Disponível em:

<http://gutenberg.spiegel.de/buch/6618/23>. Acesso em: 28 Mai. 2013.

SCHWARTZ, Jorge (Org.). Borges no Brasil. São Paulo: Editora Unesp, 2001.

WAISMAN, Sergio Gabriel. Borges and translation: the irreverence of periphery. Lewisburg: Bucknell University Press, 2005. 